\title{
Mental Well-Being Is Important Now - More Than Ever
}

\author{
Raddu Samaddar ${ }^{1}$, Subhrajyoti Bhowmick ${ }^{2}$ \\ ${ }^{1}$ Pursuing UG - B Tech In Biotechnology from Amity University, Kolkata. \\ ${ }^{2}$ Clinical Director, Peerless Hospital, Kolkata. \\ Corresponding Author: Subhrajyoti Bhowmick
}

Since the outbreak of COVID-19 till date, we have come a long way. While the health Care workers throughout the world are racing to provide the best available supportive care and treatment to patients, we are actually somewhere between hopeful and tired of the pandemic being in this long-drawn scenario than many of us might have imagined. To make something very clear, we are hoping this would end and are eagerly collecting information on the worldwide progress of making all of this come to an end. So, with all the physical stress that is being added by staying at our homes in the state of lockdown and getting updates about the cases of ever-rising spread each day, it takes a heavy toll on our minds and to overcome that is the biggest challenge of our times. We have started cursing the year 2020 with the thought that the blame game would satisfy our panicked minds.

In the past we have pandemics go on from 2-3 years (H1N1 Swine Flu Pandemic) to even more than hundred years. The credibility of healthcare system lies in the fact, how fast a treatment can be implemented and the curves of rise can be curbed. Not all Pandemics are same, a viral causative agent will pose far greater risks of an exponential spread like we are seeing now. At this point of time. We thought of focusing on certain issues that would have marked effects on our minds. Added to the fear of coming in contact with the virus, restricted flow of life is having a serious impact that is worthy of some addressal.

Understanding the importance of lockdown and abiding by it, Handling Social Isolation, Filtered Information, handling at personal and interpersonal levels, Ignoring the Rumours and addressing the emotional issues, Post Recovery Patient Assessment, Better Recognition to mental problems. Supporting near and dear ones, Dealing with the Financial crisis. My studies have come up with the conclusion that these issues seem to be the hardest combat-arenas.

\section{Looking Closer at It}

The psychological effects of the pandemic are best understood in terms of psychiatric and psychological problems that were present before the pandemic and the patho-plastic effects of the pandemic on these problems; the responses to social isolation and lockdown; the psychological response to the diagnosis, public responses to those with symptoms suggestive of COVID-19 infection, as well as the aftermath of the infection. We have to understand that lockdown is strictly a way of stopping the spread of this rapid infecting RNA Virus. The Healthcare Workers and Researchers are racing against time and trying to make the most out of the limited knowledge we have gathered and continue to gather throughout. This means, staying indoor except for buying necessities and ideally only one healthy family member making the trips when it is absolutely necessary.

Social Isolation is a major aspect that is hard to be dealt with, while the increasing use of smart phones and internet can be thanked at this hour of need to waive off that factor. Connectivity is the Key. This current period of social isolation will also exacerbate the epidemic of loneliness identified by a 2019 University of Michigan study on healthy aging in which $34 \%$ of adults aged 50 to 80 years reported feeling lonely. Studies have shown increased delusions, suicidal attempts and psychosis in recent times. But relating to that, we should make the most of what is available to us. Telemedicine is an important use of internet where the one in need could seek some professional help without a physical doctor's visit. The medicine and healthcare world is fearing the onset of a 'loneliness epidemic'.

Societal maturity will play a very important factor for this cause. Now to handle that, we have to take care of the society and stay safe at the same time. Small endeavours like, making sure every news you are 
spreading has a silver-lining of positivity within it, not harming any class of people on a personal level because he or she has caught Covid-19 infection, making your peace with the fact that the news that we are getting to hear will not always be comforting yet not panicking and dealing with them in the right way. Helping anyone and everyone in need and most importantly, if you know someone is going through a crisis that you can address and bring in some form of remedy.

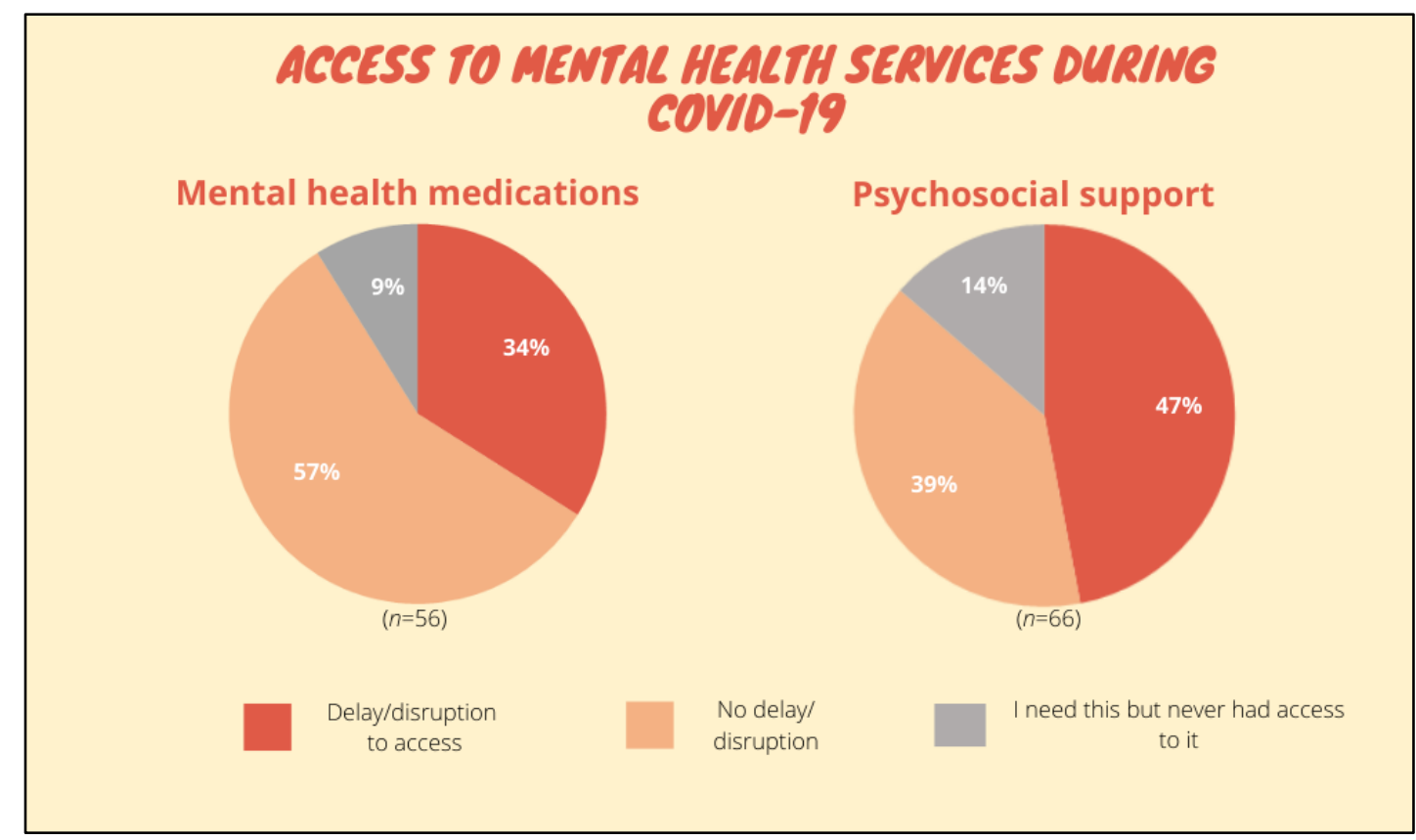

Source: UNICEF

\section{The focus speaks for itself}

The healthcare workers are taking a heavy toll of stress on their minds too. To stand and work for hours tirelessly with the fact of acceptance that supportive care is all that's available at the moment. That takes some serious attitude driven strength to carry on and keep at it. Indeed COVID-19 has impacted the mental health of the entire community in one or another manner. This has created an unprecedented mental health challenge in the face of limited specialist resources. This also means that we need to think beyond conventional strategies. We need to manage with what is available, but constantly update ourselves, almost daily. Simultaneously, we need to engage with non-psychiatric medical professionals to facilitate the psychiatric management of patients with COVID-19 infection and co-morbid physical illnesses. Digitalenabled learning and support for mental health issues need to be considered for all non-psychiatric medical professionals and frontline personnel. Online learning are equally useful for regular updates for psychiatrists as well.

\section{Hearing it from experts}

I have had the chance to gather some words of wisdom from Psychiatrist Dr. Bappaditya Chowdhury, he says, "In this trying time, we're going through three parallel epidemics simultaneously. Along with Corona virus, Economics and Psychogical epidemic creating a havoc on every section of society. We don't know to what extent and how long this crisis is going to stay. Accordingly, people are trying their best to adjust to this 'New Normal'. Here the painstaking courage shown by front line health worker, security persons and other public service personnel should be highlighted more. Their exemplary story of struggle and success should motivate and guide general population in this fightback. It's time to show solidarity, shake off ignorance, follow health advisory meticulously. Share and care together with keeping our Hopes high should be the principal in this 'New Normal' period." 
Taking all fronts under consideration, I had a chance to take some valuable inputs from renowned PsychoCounsellor Mr. Subrata Bhattacharyya on the current scenario, "Everyone has had a hard time coming to terms with the new normal of social isolation. To add to it, habitual life has been severely disrupted by the lockdown, leading to a sharp rise in anxiety, frustration, and depression among people. India has witnessed a $20 \%$ increase in the number of psychological disorders solely in the past few months of lockdown. It is of utmost importance now to focus on the very present and work to make it beautiful. We have to keep trying to think right, remain positive, and hope for the best."

\section{Hearing it from the warriors}

"Being a Covid-19 patient is very stigmatizing, it involves separation from loved ones and living with fear and anxiety as there is always a fear of infecting other people, especially the family members who are not quarantined. In this situation, support of family is of utmost important. And always remember that it is a collective fight, and by maintaining the rules and following proper guidelines and with support, self-isolation will not be too much difficult, keeping aside the society.", says Debanwita Roy Burman, 22, who has successfully recovered after being treated at CNCI, Rajarhat, Kolkata.

"Support from your family and nearest is required. Social boycotting is unhealthy. Doctors and specially nurses are unparralel. I have seen losing two of my fellow COVID warriors. It was hurting and created fear in mind. Those recovered and released gave me a ray of hope for future live together work together.", says Ajit Sarkar, 50, who is a Bank Employee and a victim of Workplace Contact Infection treated at Desun Hospital, Kolkata.

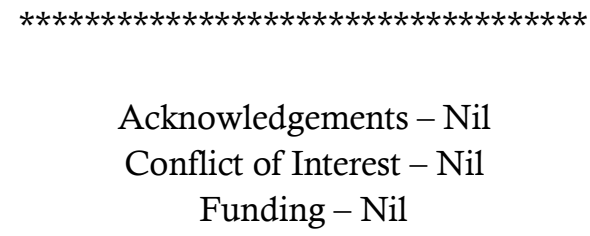

